\title{
GEOMETRIC SURVEY DATA AND HISTORICAL SOURCES INTERPRETATION FOR HBIM PROCESS: THE CASE OF MANTUA CATHEDRAL FAÇADE
}

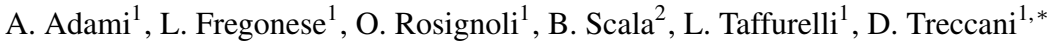 \\ ${ }^{1}$ Dept. of Architecture, Built Environment and Construction engineering (ABC), \\ Politecnico di Milano, Piazza Leonardo da Vinci 32, Milan, Italy \\ (andrea.adami, luigi.fregonese, olga.rosignoli, laura.taffurelli, daniele.treccani)@polimi.it \\ ${ }^{2}$ Dept. of Civil, Environmental, Architectural Engineering and Mathematics (DICATAM) \\ University of Brescia, via Branze, 43, Brescia, Italy - barbara.scala@unibs.it
}

Commission II, WG II/8

KEY WORDS: HBIM, planned conservation, data interpretation, laser scanning

\begin{abstract}
:
Planned conservation approach requires a sustained, long-term action to better manage the cultural heritage assets during their life cycle. Together with programmed conservation and local interventions, there is a large amount of information related to the building; it emerges the need for an appropriate tool in which to store all data. Historic Building Information Modelling (HBIM) can be an appropriate way to address this issue. In this context, the lack of automatic tools (to speed up the project) and the need for data interpretation in the process are noticeable, especially for cultural heritage items. In this paper we present a practical case study. Starting from an integrated survey of Mantua Cathedral (located in Northern Italy) we developed a HBIM model of its façade. Particular emphasis is given to data interpretation both from geometrical survey and from historical sources. The resulting model is consistent and coherent with reality. As a result, we state that the development of a HBIM model is not an automatized process. In the process, from the survey to the final model, there is the need for a deep knowledge and a deep understanding of the building, not only in term of geometrical survey but also of its historical phases, its changes in time, its materials and the construction techniques. HBIM can be a useful instrument for planned conservation, which strongly requires a coherent model to be effective and useful. A proper model, working as an integrated archive, can increase the effectiveness of planned conservation.
\end{abstract}

\section{INTRODUCTION}

Planned conservation is an operative process in which a series of actions (survey, control and design for repair or reuse of an asset) are activated and executed in a built environment with regularity, and accurately recorded in an organic and articulated system. A lot of data is available to all the actors involved in the project with different roles (owners, asset managers, technicians, users, and so on), who should update the data in relation to their different competences, so that this process continues to be implemented.

Planned conservation has become increasingly present in European and international policies and research over the last three decades (Vandesande et al., 2018). This strategy is based on the need of trying to demonstrate that a holistic and long-term vision is more effective in a logic of sustainability (Moioli et al., 2018).

Historic building information modelling (HBIM) was firstly proposed as a new system of modelling historic assets (Murphy et al., 2009); the final HBIM products are well-rounded 3D models that include details behind the object's surface concerning its methods of construction and material make-up (Murphy et al., 2013).

Several examples of applications and case studies use HBIM to model built environment and cultural heritage. They start from a survey to then model the asset by means of some specific software. Some of them also propose the HBIM as a tool for

\footnotetext{
${ }^{*}$ Corresponding author
}

planned conservation (Bruno , Roncella, 2018), (Bolognesi , Garagnani, 2018), (Dore et al., 2015), (Oreni et al., 2017), (Adami et al., 2017), (Brumana et al., 2018).

In this paper we want to study how to develop a HBIM considering the importance and usefulness of data interpretation. Data coming from geometrical survey, historical sources and even in-situ tests were collected and analysed before the development of the model. HBIM is not an automatized process, but needs user expertise and interpretation.

The case study presented, Mantua Cathedral façade, shows interesting elements that stress the need for geomatics scientists and restorers to work together for the development of a coherent model. We present a way to improve the model with geometric data interpretation and a deep knowledge of the building (its history and constructive techniques). The model becomes a sort of integrated archive for the building. In the next chapters we will present the case study chosen: after a general outline of the building we thoroughly describe its particular historical evolution; we do so because in the following chapters some insight into historical evolution is needed. Then we present the integrated survey campaign, that is quite typical. In the methodology section we explain the core of our method: prior to modelling we analysed the geometrical data together with historical sources, and made some interesting discovering about the building. Then we describe how we modelled the façade. Lastly, we make a critical analysis of the resulting model and we discuss about its relevance. In the conclusions we examine the future works and main issues arising from this paper. 


\section{CASE STUDY: MANTUA CATHEDRAL}

\subsection{General description}

The case study is the Mantua Cathedral façade. Mantua is a city located in Lombardy region, in northern Italy. In 2008, Mantua's historic centre was declared World Heritage Site by UNESCO; Mantua was the Italian Capital of Culture for the year 2016 (from www.treccani.it/enciclopedia/mantova/).

Mantua Cathedral is located in the city's historic centre, in the northern side of piazza Sordello, between the Ducale Palace and the bishop's Palace. It is built next to the seminary. The Cathedral is composed by five aisles and two rows of chapels; behind the transept there is an apse and on its west side there are a sanctuary and a second smaller church. The covering system is quite complex: the main nave is covered by a planar lacunar ceiling; the following aisles (from the center to the exterior) by a barrel vault, then again planar lacunar ceilings for the next one, and alternating lacunars and small domes for the last row. The building plan is complex as well and presents many ancillary rooms. The attics are intricate and not similar one to the other, especially when close to the façade. In fact, in the western attic, just behind the façade, there is a big room with windows, while on the eastern one there is just a small empty space. On the outside, the façade is covered in white Carrara marble. The central portion is subdivided by four Giant Order Corinthian pilasters holding a tympanum. The two side portions are decorated by a double order of Tuscanic pilasters ending on a horizontal entablature, adorned with medallions and other statues. The main portal is accompanied by Tuscanic columns that hold Ionic columns for the loggia. Figure 1 shows this configuration. The façade of this building represents an interesting case study because of its complexity, as in: the repeated decorative elements; the dissimilar setting of the attic enviromnents behind the façade; the eventful historical evolution along which it was rebuilt and modified several times.

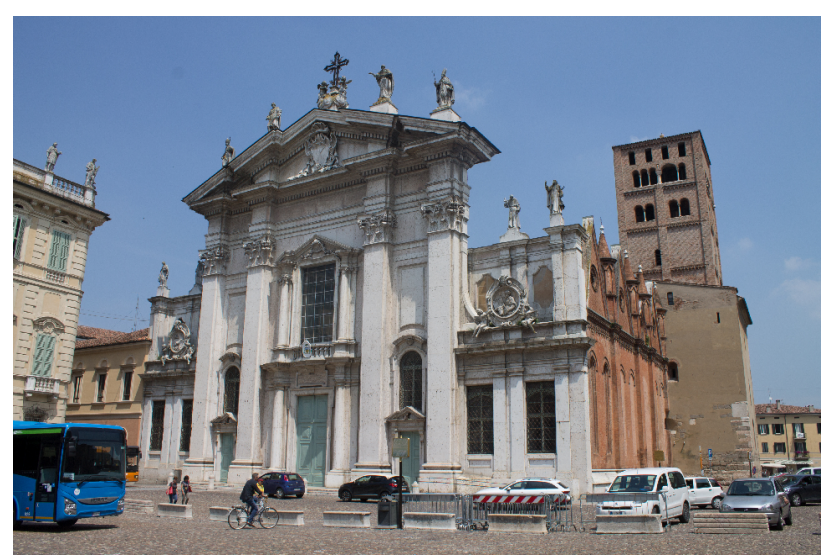

Figure 1. Mantua Cathedral Façade, photo by authors

\subsection{Historical evolution}

There are only few historical sources that describe Mantua Cathedral in the past, and they mainly refer to the 1500 s, when architect Giulio Romano made some interventions. The only plans available refer to a survey made in 1980s. Furthermore, most of the sources refer to indoor space and very few to the main façade.

The current aspect of the Cathedral is the result of many consequential changes during time. As suggested by (Piva,
1988) it is possible to define three main phases: Romanesque, Late Gothic and 16th century interventions.

Some chronicles state the Cathedral foundation in 313 a.D. when existed two twin churches, possibly connected, dedicated to San Pietro and to San Paolo (Gibellini, 2004). Contrarily, according to (Paccagnini et al., 1960), the foundation date remains undefined, but it could go back to the firsts year of Christianity. However, it is sure that in 894 a.D. there was a great fire that destroyed the building and its content. The church was re-built in the 11th Century and from that time on the Cathedral was bigger, more central to the city and with a churchyard (Brunelli, 2009).

The Romanesque appearance of the Cathedral is well described by (Marani, 1957). He studied the description of the structural parts of the church, written by Giacomo Daino in 1545. Marani concluded that the Roman Cathedral had three aisles subdivided by pillars, no chapels on the sides, a wide crypt under the tribune and a deep apse. He do not say anything about the façade.

In late gothic era (1400-1500) Francesco I Gonzaga assigned a reconstruction of the church façade to two Venetians architects: Pier Paolo and Jacobello dalle Masegne. We do not know exactly what they realised, but we can guess it by looking to a painting made by Domenico Morone: La cacciata dei Bonacolsi (15th century), which is currently kept in the Ducale Palace, in Mantua. The façade was made with polychrome marble, it had a galilee porch, rose windows and pinnacles. The brothers also modified the church plan, and added some chapels on both sides decorated with marble and terracotta spires and cusps. Marani gives the description of a probable church plan before and after the dalle Masegne interventions.

On 1st April 1545, during night, a fire damaged the Cathedral; cardinal Ercole Gonzaga started the reconstruction of the building, assigning the task to Giulio Romano. Among the many documents and books discussing Giulio's project, we refer to (Piva, 1988), who collected more information from many sources, among which the Mantua Diocesan Archive. Giulio Romano started immediately the construction site, in fact just a month after the fire they began posing pillars and marble columns. The architect concentrated his intervention on the inner part of the building, except for transept, presbytery and apse, that have been realized later. He left untouched the pre-existing aisles but inserted the new elements in the old structures. He proposed five aisles with two external rows of adjoining chapels. Giulio chose a varied roofing systems: planar lacunar ceiling for the central nave, barrel vault with stucco decorations for the median aisles, again planar lacunar ceiling for lateral aisles and small domes alternate with barrel vaults for the two rows of external chapels. In autumn 1546 Giulio Romano died and other architects took over him. We can say that in the nowadays Cathedral only the five aisles with columns and the roofs should be considered made following Giulio's project and indeed they were built when he was still alive. We know something more about the building techniques used during Giulio's time thanks to some restoration works on the Cathedral made from 1999 to 2004; they also allowed to make a comparison between the Cathedral in Roman times and after 1500s interventions (Volpi Ghirardini, 2014).

In 1547-1548 architect Girolamo Genga designed a new façade. We can better notice the Genga intervention by comparing two paintings: La cacciata dei Bonacolsi by 
Domenico Morone in the 15th century and L'imperatore nomina Gianfrancesco Gonzaga marchese di Mantova by Tintoretto in 1579. Supposing Tintoretto drew the reality and not a project, we can understand some works that took place: the extension of the stone decoration to the lateral zones; the closure of the central rose window; the removal of the spire over the galilee, substituted by a serliana; the Gothic decorations inside the windows seem disappeared; the banister over the galilee is different with respect to the old one; there are new windows in the lateral portions; there is a new partition of the façade with pilasters and an entablature.

In 1775 the façade became so damaged that a strong restoration had to be made. Bishop Antonio Guidi di Bagno commissioned it to Nicolò Beschiera, an Austrian army engineer, from Rome, in 1756-1761. Beschiera's intervention was inspired by Baroque churches in Rome and the new facing was made by white Carrara Marble. This last intervention is still visible on the elevation of the Cathedral we currently see from piazza Sordello.

\subsection{Survey campaign}

Considering the complexity level of this cultural heritage asset and given that we were interested in the geometry of the entire building, we developed an integrated survey that merges together data from a topographic network, laserscanner and photogrammetry.

The topographic network, that was the skeleton of our survey, has been conceived by using both indoor and outdoor points, some traverses and some IGM (Italian Military Geographic Institute) points to georeference the survey. The pointclouds from laserscanner and photogrammetry were registered using the topographic network as a framework. We adjusted the topographic network by using the least square method.

Photogrammetry was used only to perform the survey of the external side of the roofs, so to highlight the conservation status of tiles and roof structure in general. Photos were taken by using a lift platform to reach the required height. All the other part of the Cathedral were surveyed with a laserscanner and an iStar camera was used to colour the pointclouds made in the indoor spaces like the aisles and the chapels.

The Cathedral complete survey was composed by merging together 471 point clouds from different survey campaigns: the left attic (surveyed in November 2017), the external roof structure (taken in early 2017), the remaining part of the Cathedral (surveyed from January 2018 to June 2018) and the Tower Bell (surveyed in Autumn 2018). Figure 2 shows some deliverables obtained using pointclouds of the cathedral.

The instruments used were Leica total station TS30, Leica laserscanner HDS7000 and a camera Canon EOS 5D Mark III. Photogrammetry was managed using Agisoft Photoscan. We used Leica Cyclone to manage laserscanner data and to prepare them for their usage in Autodesk Revit through Leica Clowdworx plug-in.

\section{METHODOLOGY}

BIM process requires that the building is drawn as if you are virtually re-building it (Bonazza et al., 2017), so you have to somehow follow the same process utilized by the craftsmanship
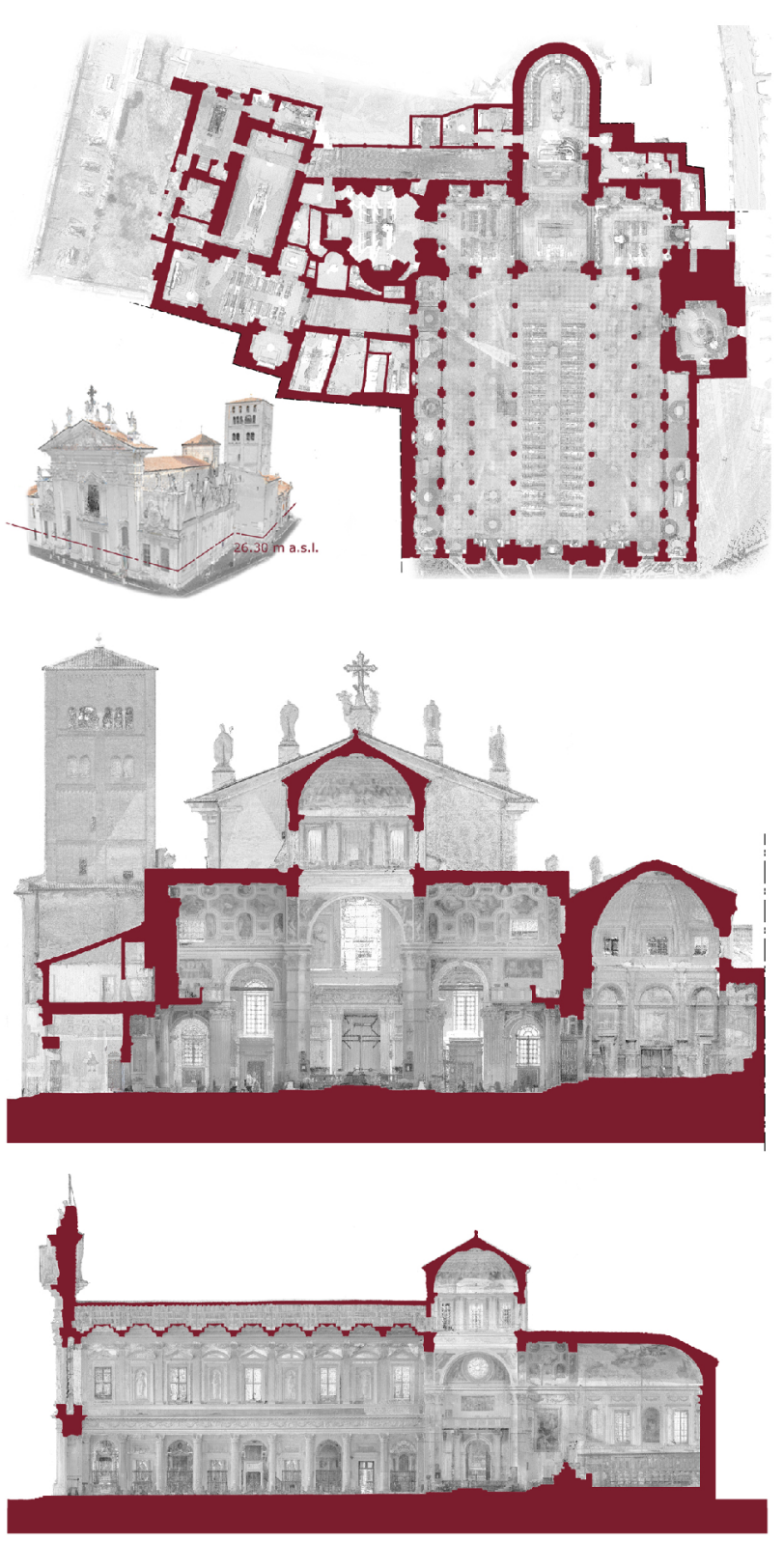

Figure 2. Some of the deliverables of Mantua Cathedral survey obtained from the pointclouds. Top: main plan and perspective external view. Middle: east-west transversal section. Bottom: north-south transversal section.

that built it. For a cultural heritage item it means the need to know how it was built. Prior to modelling it is important to define the model characteristics and how to realize them. From the survey campaign we have a huge amount of geometrical information. The building is described with high accuracy, but the survey gives us only the surface, to develop the model we have to understand what happens behind such surfaces. Plus, Autodesk Revit (the software we choosen) has some restrictions and prefixed elements (walls, floors), so we need to define those elements by understanding how the building works. The methodology we followed is described in Figure 3: the interpretation of geometrical data, historical sources and building techniques helped us in making some hypotheses that together with the purpose of the model will lead us to a modelling phase and the final Historic BIM model. 


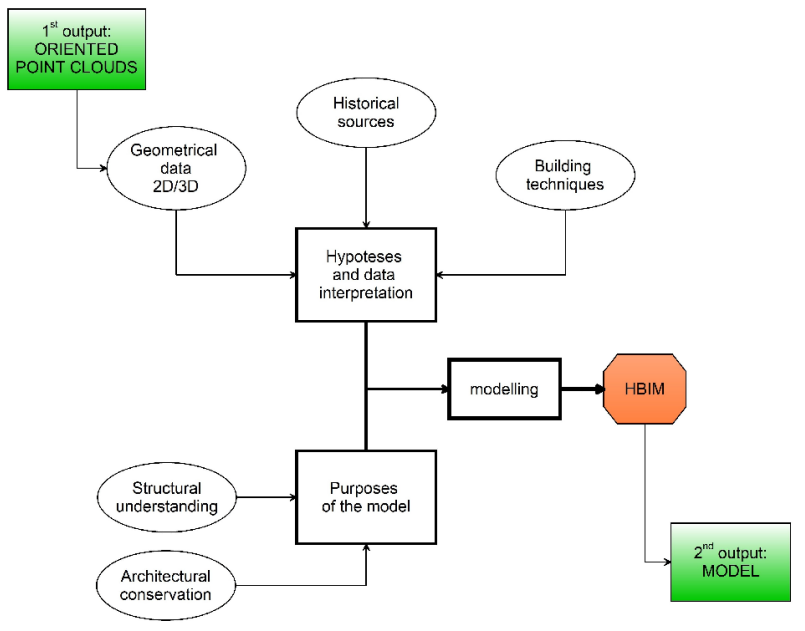

Figure 3. Flowchart explaining the proposed methodology: starting from the pointclouds and basing on hypoteses and data interpretation and considering the possible purposes of the model

\subsection{Hypoteses and data interpretation}

We started with describing something we noticed on site during the survey campaign. In the eastern attic, we see two arches on the façade wall: one in correspondence with the eastern side aisle and one over the chapel rows; near the last dome close to the front wall, we see again an arch, and under this arch we see a portion (closed) of a circular window, with its moulding (Figure 4).
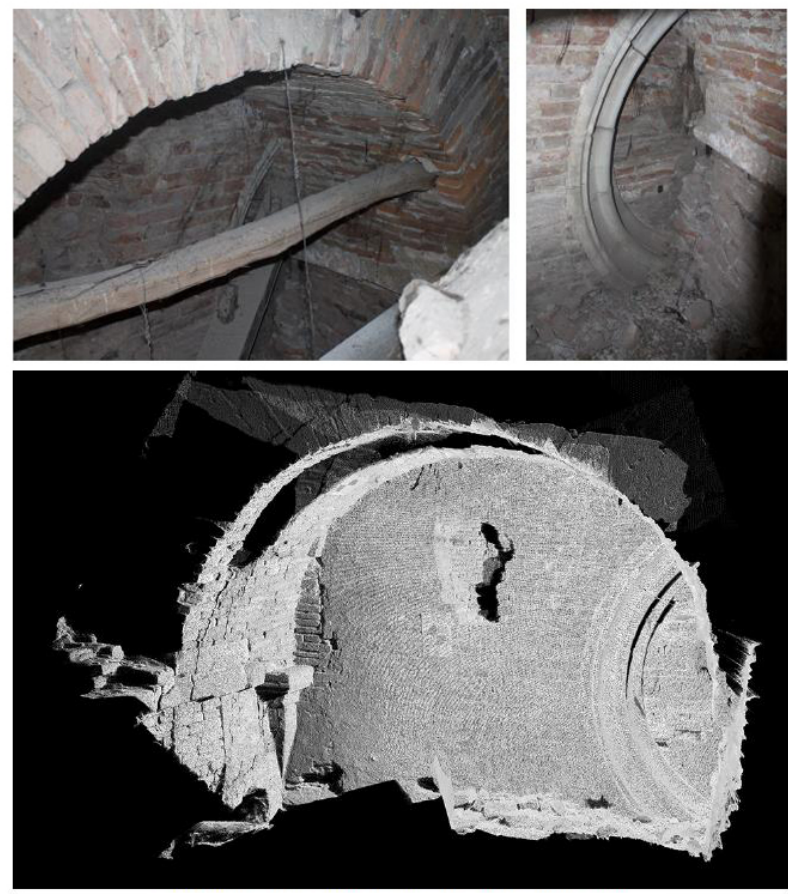

Figure 4. Photos and pointcloud representing the indoor side of the façade wall in the extreme eastern attic. Top left: photo of a big arch in the façade wall, over the chapel rows, in right attic. Top right: Detail of a closed window in the wall under the arch. Bottom: pointcloud view of the same element of top images.
Those two elements, and in particular the gothic window, are fundamental to understand the façade structure. We have to define how the arches work (structurally) and how they are connected with the rest of it. Similar arches are probably present also in western attic, but the presence of enclosed rooms hides them. It was very important to date that window, so we compared the painting by Domenico Morone in the 15th Century, representing the Gothic layout with an orthophoto of the current configuration generated from point clouds of our survey. We superimposed the two images and changed the transparency we can easily assume that the window found in the wall in the right attic is probably the one presents in Gothic layout (Figure 5).
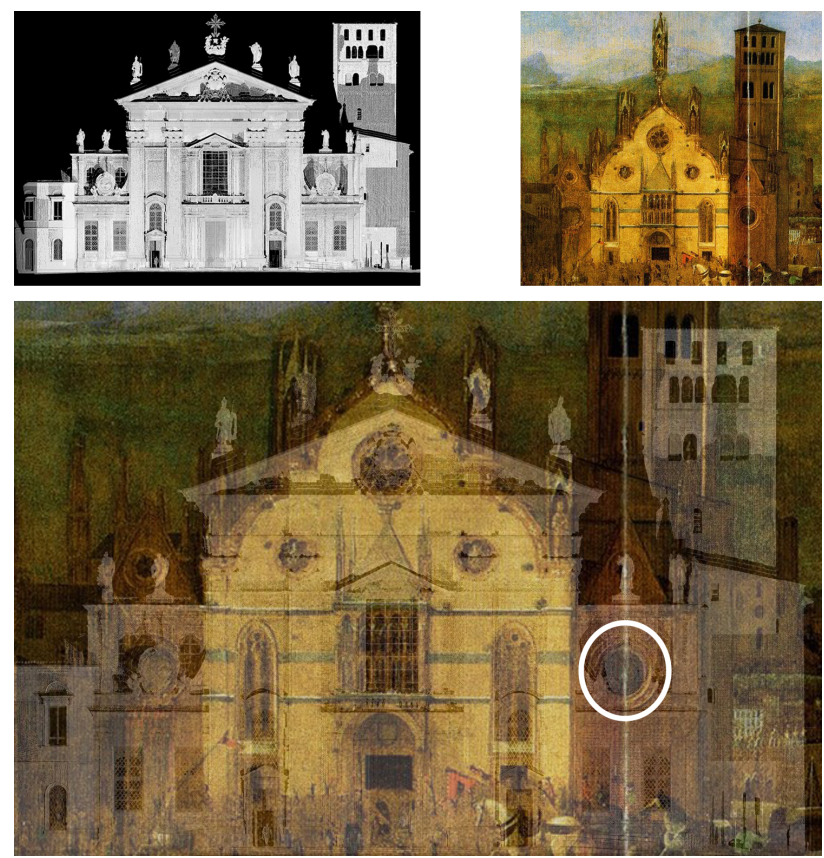

Figure 5. Top left: orthophoto of the façade generated in Cyclone from pointlcouds. Top right: portion of a painting made by Domenico Morone in 15th Century, representing the Gothic façade. Bottom: Superposition of the top images, the circular window previously found and descripted on Fig. 4 is here marked with a white circle.

Considering what said so far, we concluded that today's façade is made by two walls, juxtaposed; the more external one (facing the piazza) was part of the old Gothic façade and the more internal one (facing the indoor of the Church) was built later, probably during the 1500 s interventions. Basically, we have a façade made by two leaf walls, and on the outer side we have a layer of stone plates.

To support our deductions and to check if the two structural wall hypotheses is consistent along the whole height, we made several horizontal sections along its elevation. More specifically, to derive geometric information from the point clouds we decided to use Leica CloudWorx for AutoCAD; it is a plug-in software for using as-built point cloud data-captured by laser scanners- directly within AutoCAD. Using this plug-in we can see the whole point-clouds and also we cut slices on $\mathrm{X}$, $\mathrm{Y}$ or $\mathrm{Z}$ axes, managing their thickness and position, moving it up or down and left or right. We can describe this approach as an analysis that is similar to a medical computer tomography scan. Doing so we noticed that the two walls are consistent 
in both attics, but also at ground level. The hypotheses seem correct.

Now that we have enforced our hypotheses on how the structure behaves, we know which are the elements that constitute it and how we should model it; but we still need to define the geometry (thickness) of those walls. Considering the historical significance of this building it was not possible to make some core drilling or other destructive tests on site, so we had to estimate the thickness only from the point clouds coming from our survey and the knowledge of building techniques. Again, the geometric survey was the tool used to define it. In fact, by using the same sections that confirmed the hypotheses, we defined the thickness of the two structural walls and of the stone layer.

Now we are able to define how the building is made and now we can start modelling.

\section{2 modelling the façade}

There are several possibilities and software to create a HBIM. The desiderata of the project required to develop it using a commercial software; according to 2018 UK National BIM Report (U.K., 2018) Autodesk Revit is the most used application for technical offices. Furthermore, Autodesk Revit is a software mainly devoted to new constructions, so we wanted to test its possibilities with historical buildings.

Starting from our understanding of the façade described in previous paragraphs, we can make the model by using three "wall" elements: one for each of the two structural walls, containing some void-shapes for the arches seen in the attics. A last wall element represents the white stone layer and all its decorative elements. Regarding the decorations, we tried to represent them as parametric elements modelled by means of loadable families. To do so, we recognized some repeatable elements and modelled them singularly, then we loaded them in the final model as many times as necessary. Those elements are: the Corinthian giant order pilasters, Tuscanic pilasters, the lateral windows, the lateral door and its window, the central door and its window, and the tympanum.

Figure 6 shows an orthophoto of the façade generated from the point cloud: in blue we depicted the six repeatable elements. We modelled them by using the Autodek Revit Family Editor. This software environment, unlike Autodesk Revit main environment, does not allow to open point clouds. To overcome this problem, we decided to export a portion of point cloud as a .dwg file and import it inside the Revit Family Editor. We modelled all the six families separately and as last step we loaded them into a final Revit model. The mouldings were modelled extracting the extrusion profile from the point cloud in AutoCAD. To place these families we kept as reference the point cloud, imported in Autodesk Revit by using the Leica Clowdworx plug-in.

The final model (Figure 7) is composed by the three walls already discussed: two structural and a third one that is a stone layer with its decorative elements, doors, windows and pilasters. In the image (Figure 8), the two structural walls are hidden behind the surface.

At last, we tried to investigate the structural capability of the model and Autodesk Revit interoperability with structural analysis software. To do so, we selected as "structural" the two

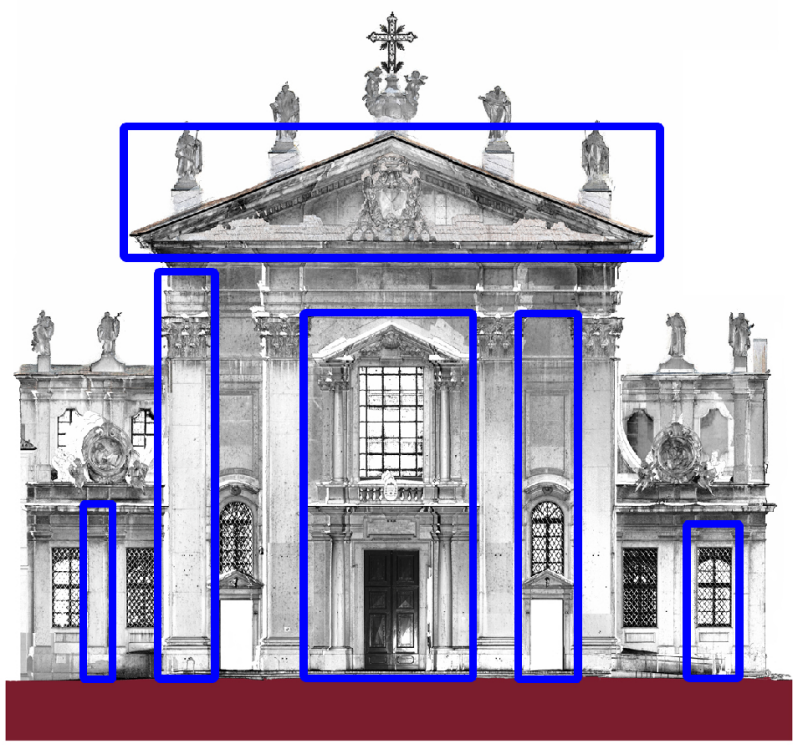

Figure 6. The six families that will be developed in Autodesk Revit, marked with blue rectangles, over an orthophoto of the façade, generated in Cyclone from the pointclouds.

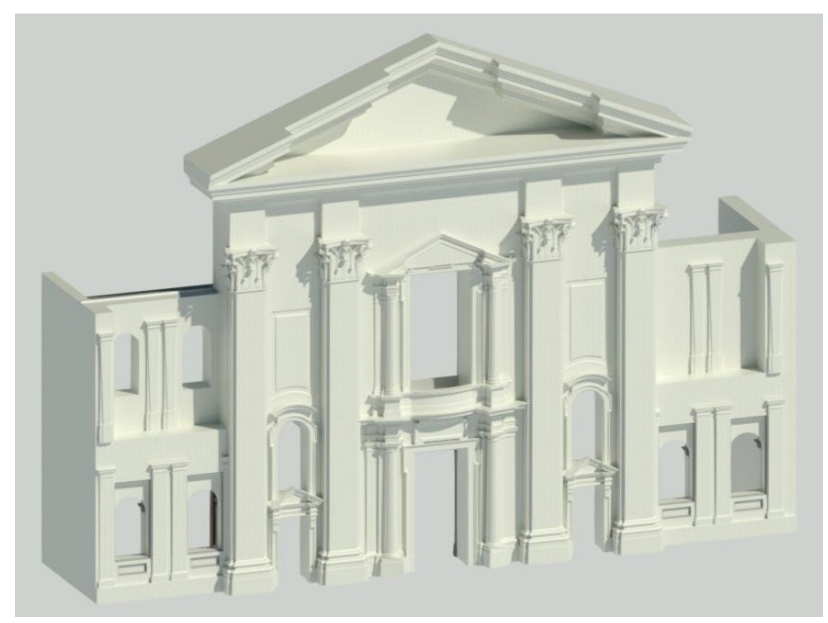

Figure 7. Rendering of the final façade model, from Autodesk Revit.
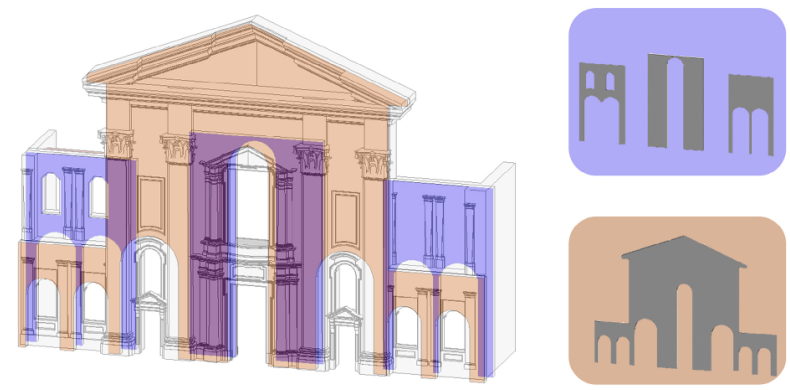

Figure 8. Graphical explanation of the composition of the façade model: two structural walls and one architectural wall with all the decorative elements. 
structural walls of the façade and we selected as "architectural" the external layer. This was useful when we tried to export the entire BIM model into MidasGEN, a structural analysis software. MidasGEN imported only the structural elements from the final model; the two structural walls were in the correct position and were imported as meshed plate elements.

\section{DISCUSSION}

From the work we presented, we can highlight that such models come to life after an interpretative labour; this interpretation has emerged after an on-site inspection, a geometrical survey and historical analysis. We believe that the more you know about the building, the more coherent the final HBIM model will be. In our case, we made our reasoning only considering the geometrical data, historic sources and what is visible of the building. We did not make any specific exams on construction materials, or any other tests to define the walls resistance or thermal analysis and so on: these are further data that can be added later on to the model. The presented methodology led us to a model that represent the reality and that can be helpful to different kind of users and technicians from different disciplines; in the same model we have structural elements and architectural details. We can deduce that the biggest effort in the modelling phase is understanding how the building behaves. The modelling is only the last stage of the BIM process; when we make a survey, the model is not produced automatically, but we need to reason about the data obtained and need to understand how the model behaves. This surely eases the HBIM process; in our case study we noticed a significant amount of time saved in developing the families. This approach is more rational and requires lots of groundwork. For sure the ideal model development requires teamwork: someone studying the history and someone surveying geometry, who (at the end) bring and explain their findings to the modelers.

\section{CONCLUSIONS}

We presented a practical case study validating our considerations that deep knowledge of the building is mandatory to develop an effective model. This deep knowledge comes from an interpretation of all the data collected about the building (e.g. geometry, history and evolution, materials, sensors readings and so on) from several sources (such as surveys, historical documents, archive papers, inspections, sensors). A primary suggestion is that the development of a HBIM model is not an automatized process. The methodology presented combines all the source materials and data and analyses them before modelling. Only after an interpretation of the data we can model the building and develop the task. This kind of approach fits in with planned conservation requirements, where the HBIM model becomes an integrated archive to store and represent all the data. It is a coherent tool where all the actors involved in planned conservation can meet. In this process coherence becomes more important than geometry. For the future we want to complete the whole building by following the same approach. We are positive that this object will be suitable for adding data coming from sensors and other inspections to be made on the building. There is also room for improvements of the loadable families.

\section{ACKNOWLEDGEMENTS}

The presented work has been supported by Cariplo Foundation, through the project Buone Prassi e nuove tecnologie per la conservazione programmata: tra continuità e innovazione. We want to thank the Mantua diocese, in the person of arch. Alessandro Campera, bishop's delegate for relations with Superintendence. This paper is part of the SIR (Scientific Independence of young Researchers) research project (code n. RBSI144B5K) on Building Information Modelling for the planned conservation of Cultural Heritage: even a Geomatic question, funded by MIUR.

\section{REFERENCES}

Adami, A., Scala, B., Spezzoni, A., 2017. Modelling and accuracy in a bim environment for planned conservation: The apartment of troia of Giulio Romano. Int. Arch. Photogramm. Remote Sens. Spatial Inf. Sci., XLII-2/W3, 17-23. https://doi.org/10.5194/isprs-archives-XLII-2-W3-17-2017.

Bolognesi, C., Garagnani, S., 2018. From a point cloud survey to a mass 3D modelling: Renaissance HBIM in Poggio a Caiano. Int. Arch. Photogramm. Remote Sens. Spatial Inf. Sci., XLII-2, 117-123. https://doi.org/10.5194/isprs-archives-XLII-2-117-2018.

Bonazza, M., Pozzoli, S., Villa, S., 2017. Autodesk Revit 2018 per l'Architettura. Guida completa per la progettazione BIM. Tecniche Nuove.

Brumana, R., Della Torre, S., Oreni, D., Cantini, L., Previtali, M., Barazzetti, L., Banfi, F., 2018. Scan to hbim-post earthquake preservation: Informative model as sentinel at the crossroads of present, past, and future. E. Ioannides, M.and Fink, R. Brumana, P. Patias, A. Doulamis, J. Martins, M. Wallace (eds), Digital Heritage. Progress in Cultural Heritage: Documentation, Preservation, and Protection. EuroMed 2018. Lecture Notes in Computer Science, 11196, Springer, Cham, 39-51.

Brunelli, R., 2009. La Cattedrale di Mantova. La Cittadella, settimanale dei cattolici mantovani, in collaborazione con: Parrocchia di San Pietro in Cattedrale e museo diocesano Francesco Gonzaga, Ciliverghe (BS).

Bruno, N., Roncella, R., 2018. A restoration oriented HBIM system for cultural heritage documentation: The case study of parma cathedral. Int. Arch. Photogramm. Remote Sens. Spatial Inf. Sci., XLII-2, 171-178. https://doi.org/10.5194/isprs-archives-XLII-2-171-2018.

Dore, C., Murphy, M., McCarthy, S., Brechin, F., Casidy, C., Dirix, E., 2015. Structural simulations and conservation analysis-historic building information model (HBIM). Int. Arch. Photogramm. Remote Sens. Spatial Inf. Sci., XL-5/W4, 351-357. https://doi.org/10.5194/isprsarchives-XL-5-W4-351-2015.

Gibellini, C., 2004. Mantova. Skira.

Marani, E., 1957. Una ricostruzione del Duomo di Mantova nell'età Romanica. Bollettino storico mantovano, Num. 7, July-September 1957. 
Moioli, R., Boniotti, C., Konsta, A., Pili, A., 2018. Complex properties management: Preventive and planned conservation applied to the Royal Villa and Park in Monza. Journal of Cultural Heritage Management and Sustainable Development, 8(2), 130-144.

Murphy, M., Mcgovern, E., Pavia, S., 2009. Historic building information modelling (HBIM). Structural Survey, 27(4), 311-327.

Murphy, M., McGovern, E., Pavia, S., 2013. Historic Building Information Modelling - Adding intelligence to laser and image based surveys of European classical architecture. ISPRS Journal of Photogrammetry and Remote Sensing, 76, 1-7.

Oreni, D., Karimi, G., Barazzetti, L., 2017. Applying bim to built heritage with complex shapes: The ice house of filarete's ospedale maggiore in milan, Italy. Int. Arch. Photogramm. Remote Sens. Spatial Inf. Sci., XLII-2/W5, 553-560. https://doi.org/10.5194/isprs-archives-XLII-2-W5-553-2017.

Paccagnini, G., Marani, E., Perina, C., 1960. Mantova: le arti. Mantova: la storia, le lettere, le arti, v. 2,pt. 1, Istituto Carlo d'Arco per la storia di Mantova.

Piva, P., 1988. L'"altro" Giulio Romano: il duomo di Mantova, La chiesa di Polirone e la dialettica col medioevo. Officina Grafica Ceschi, Quistello.

U.K., 2018. National bim report. www.thenbs.com/knowledge/the-national-bim-report-2018.

Vandesande, A., Balen, K., Della Torre, S., Cardoso, F., 2018. Preventive and planned conservation as a new management approach for built heritage: from a physical health check to empowering communities and activating (lost) traditions for local sustainable development. Journal of Cultural Heritage Management and Sustainable Development, 8(2), 78-81.

Volpi Ghirardini, L., 2014. La realizzazione del disegno giuliesco per le navate del duomo di mantova. Giulio Romano e l'arte del Cinquecento, Franco Cosimo Panini, 83-90. 